\title{
An Analysis of War Weaponry Trauma Victims from a Medical College Setting in Kashmir Valley
}

\author{
Mumtazdin Wani, Mushtaq Chalkoo*, Peer Hilal Ahmad Makhdoomi, Ankush Banotra, Awhad Mueed, \\ Yassar Arafat, Syed Shakeeb
}

Government Medical College, Srinagar, India

Email: *mushtaq_chalkoo@rediffmail.com

How to cite this paper: Wani, M., Chalkoo, M., Makhdoomi, P.H.A., Banotra, A., Mueed, A., Arafat, Y. and Shakeeb, S. (2017) An Analysis of War Weaponry Trauma Victims from a Medical College Setting in Kashmir Valley. Surgical Science, 8, 9-18.

http://dx.doi.org/10.4236/ss.2017.81002

Received: December 21, 2016

Accepted: January 9, 2017

Published: January 12, 2017

Copyright $\odot 2017$ by authors and Scientific Research Publishing Inc. This work is licensed under the Creative Commons Attribution International License (CC BY 4.0).

http://creativecommons.org/licenses/by/4.0/

\begin{abstract}
Background: Kashmir valley, being a known conflict zone keeps on receiving war victims due to scuffles between civilians and the government forces. Such upsurges have been noted in the recent past in 2008 and 2010; however, a new face of upheaval took place in the month of July 2016. Herein, we present an analysis of 500 abdominal trauma victims reported to our department at Government Medical College Srinagar, Kashmir, India. Methods: Government Medical College Srinagar Kashmir is a tertiary care teaching hospital situated in the heart of Kashmir valley. Being one of the referral hospitals, for trauma, we received a total figure of 6149 trauma victims out of which 500 were purely of abdominal in nature managed by the department of surgery. The study conducted was a short analysis of these abdominal trauma patients that reported from 8th July to 8th November 2016. Results: The result of analysis of 500 abdominal trauma patients is reported herein. The male female ratio of patients was 19.8:1 (male $=95.2 \%$, female $=4.8 \%)$. The age range was from 5 years to 65 years with majority reported in the age range of 15 - 30 years. The number of bullet injuries was $=85$ and the pellet injuries were $=349$. The commonest organs involved were small intestines, spleen, large bowel and liver in descending order. Penetrating injuries were seen in $=60.4 \%$, non-penetrating were seen in $=39.6 \%$. The patients were grouped into conservative, non operative and operative group. The commonest morbidity observed was wound sepsis and a total mortality reached to a figure of $2 \%$. Conclusion: This short study of analysis of trauma victims has explored the newer horizons of trauma management and we believe and conclude that specialized trauma hospitals with skilled manpower and modern gadgets of handling trauma is need of an hour especially in developing countries like ours.
\end{abstract}

\section{Keywords}

Abdominal Trauma, Pattern, Morbidity, Mortality, Management 


\section{Introduction}

Trauma is a growing menace and killer of mankind. There are various modes of trauma among which the road traffic accidents, natural catastrophes like fire, earth-quacks, tsunami, and floods have taken a lead in killing mankind in bulk. However, over last few decades, a new dimension of trauma has cropped up as a result of, man to man conflict, upheavals, uprisings, and terrorist activities. It is a global challenge to handle it. The medical personnel especially the surgeons are ought to handle the trauma victims. It needs a gamut of trained personnel, modern gadgetry and sophisticated triage centres for the management of trauma victims as a unit. Abdominal trauma is an injury to abdomen; it may be blunt or penetrating and may involve damage to the abdominal organs [1]. The signs and symptoms may include abdominal pain, tenderness, rigidity and bruising of the external abdomen. Abdominal trauma presents a risk of serious blood loss and infection. Diagnosis may involve ultrasonography, computed tomography and peritoneal lavage and treatment may involve surgery [2]. Injury to the lower chest may cause splenic or liver injury [3]. Abdominal trauma is divided into blunt and penetrating types, while penetrating abdominal trauma is usually diagnosed on clinical signs; diagnosis of blunt abdominal trauma is more likely to be delayed because the clinical signs are less obvious. Penetrating trauma is further sub divided into stab wounds and gunshot wounds which require different methods of treatment [4]. The initial treatment envisages stabilizing the patient enough to ensure adequate airway, breathing and circulation and identifying other injuries. Surgery may be needed to repair injured organs. Laparotomies are often performed in blunt abdominal trauma and is urgently required if an abdominal injury causes a large potentially deadly bleed [5]. Abdominal injury needs a prompt diagnosis otherwise a worst outcome is associated. Delayed treatment is associated with high morbidity and mortality, if perforation of gastrointestinal tract is superadded.

\section{Material and Methods}

Our hospital is placed in the centre of Kashmir valley and is a tertiary care teaching hospital. It caters to a huge population of the Jammu and Kashmir state of India. We do not have well structured and designed trauma centre in our state and the only few centres that cater to these trauma victims are available with us. Pre hospital triaging, transportation and resuscitative measures are not handy to these victims, which adds to their mortality; who otherwise could have been saved. We report an analysis of the trauma victims from our medical college as a result of current upheaval that took place in valley from $8^{\text {th }}$ July 2016 to $8^{\text {th }}$ November. The study was performed in the department of surgery after obtaining ethical clearance from the ethical committee of the institution. The trauma victims were received in our triage centre and a fleeting examination and triaging was performed by our team of residents and the abdominal injuries screened, were shifted to our general surgical armamentarium. A total of 500 patients were managed in the current turmoil of which $55 \%$ were given a conservative trial of treatment, $3 \%$ received a non-operative mode of management while as a $42 \%$ of them were taken for surgical intervention.

Baseline investigation was carried out after resuscitation of trauma victim. A skeletal 
survey of abdomen, thoracic cavity and peripheral limbs by radiography in majority of the patient was performed. The patients who presented with shock and hemoperitonium were directly taken for operative intervention and FAST preoperatively, in theater setting was performed. The patients also underwent FAST in their respective wards. The patients, who were apparently stable but having clinical suspicion of intra-abdominal injury with doubtful findings on ultrasound, were subjected to CT SCAN of abdomen (Figures 1-3). The criteria for laparotomy were laid and results were analysed after surgery.

\section{Results}

The study of analysis of war weaponry trauma victims from our medical college from Kashmir valley exhibited a different scenario of presentations from the studies already published prior to this. The age profile of our sample study of 500 victims showed a preponderance of young age group. The victims in age range of 15 - 30 years (80\%) made the big chunk of study sample. Around 56 were in an age group of $31-45$ years $(11.2 \%)$. The results of the age distribution are depicted in Figure 4.

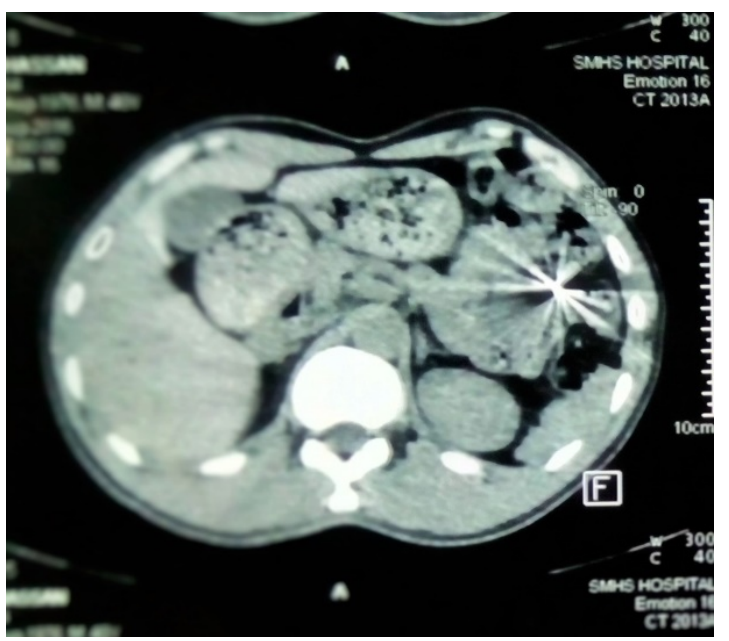

Figure 1. CECT abdomen showing pellet in splenorenal area.

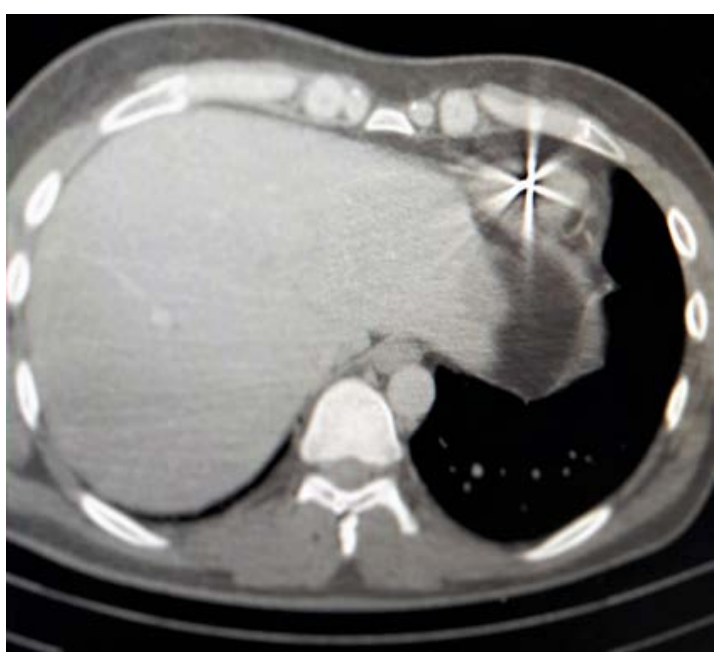

Figure 2. CECT abdomen with pellet in area of left lobe of liver. 


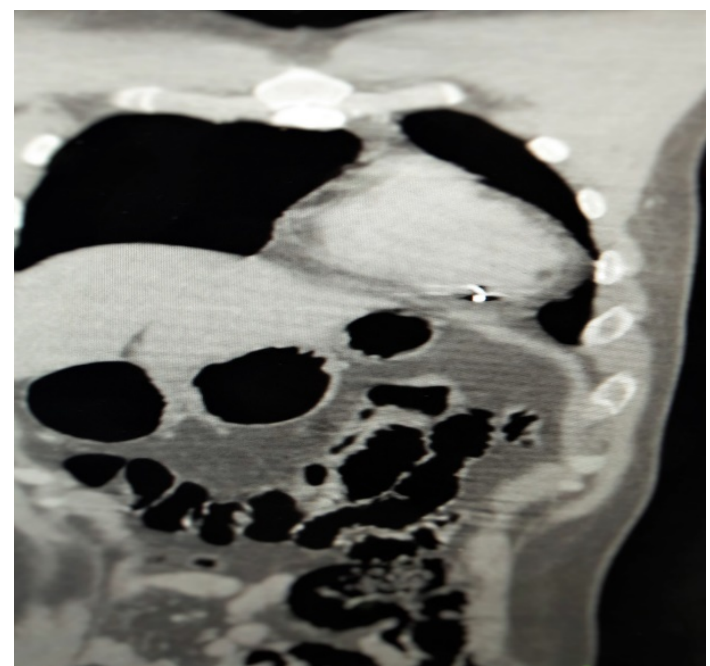

Figure 3. CT showing pellet near pericardium.

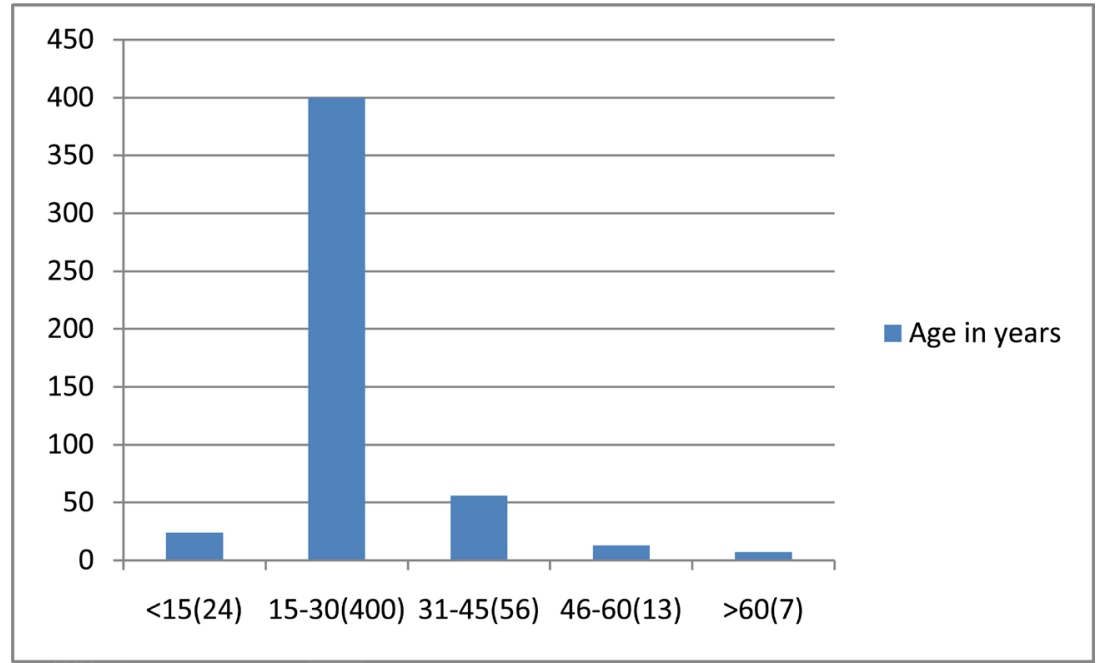

Figure 4. The commonest age of trauma victims reported in the age group of 15 - 30 years.

\section{Age distribution in abdominal trauma:}

Interestingly, we found that females too were involved in the turmoil and fell victims to the war weaponry. However $95.2 \%$ were males and around $4.8 \%$ were females involved with abdominal trauma. The pie chart in this regard is shown below as Figure 5 .

\section{Sex distribution of trauma victims:}

The analysis showed a peculiar mode of injury as $69.8 \%$ (349) presented with pellet injuries of abdomen, back, flanks. Around 17\% (85) reported with bullet injury of abdomen. 4.4\% (22) victims were injured by shell and victims also reported with a physical assault to the tune of $8.8 \%$ (44). Table 1 given below is self explanatory.

\section{Mode of injury:}

The clinical history and examination of trauma victims revealed majority of penetrating abdominal wounds comprising of $60.4 \%$ (302) and 39.6\% (198) were labeled as blunt abdominal trauma as shown below in Figure 6 .

\section{Pattern of abdominal trauma:}

The clinical presentation of the victims was varied, however, majority of them pre- 
sented with pain abdomen and hemoperitonium amounting to $42 \%$ and $41.4 \%$ respectively, as is shown in Table 2.

\section{Clinical presentation of abdominal trauma:}

Different modalities of treatment based on history, clinical presentation, pattern and mode of injury were selected. Around $55 \%$ of patients received a conservative line of treatment and $42 \%$ required operative intervention. However $3 \%$ were managed nonoperatively, as is shown in Figure 7.

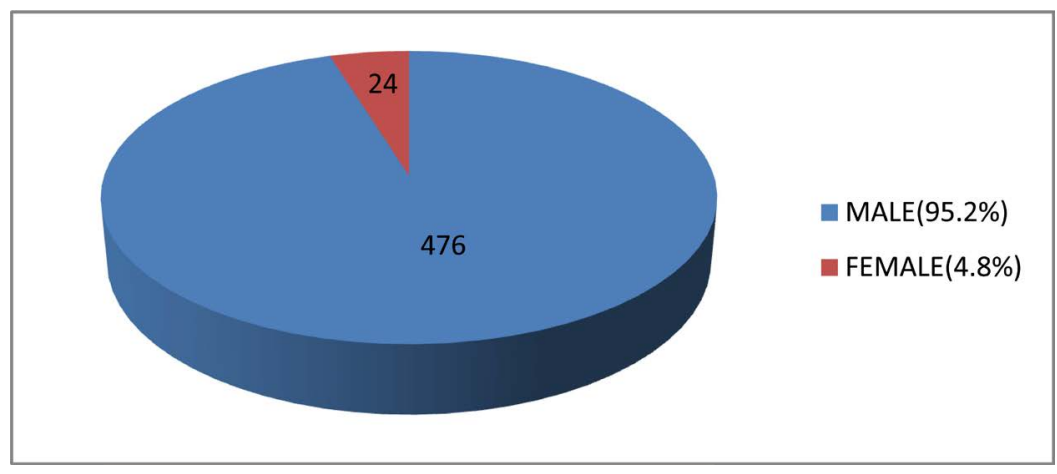

Figure 5. The pie chart showing male female distribution of trauma victims.

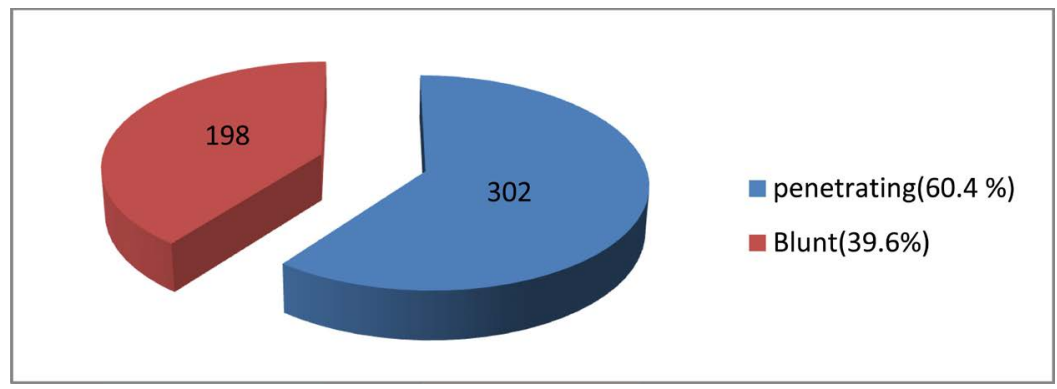

Figure 6. Pie chart showing pattern of abdominal trauma.

Table 1 . The majority of trauma victims analysed were peculiarly having pellet injury.

\begin{tabular}{ccc}
\hline MODE OF INJURY & NUMBER OF PATIENTS & PERCENTAGE \\
\hline PELLET INJURY & 349 & 69.8 \\
BULLET INJURY & 85 & 17 \\
SHELL INJURY & 22 & 4.4 \\
PHYSICAL ASSAULT & 44 & 8.8 \\
\hline
\end{tabular}

Table 2. The majority of patients presented with mixed presentation of clinical symptoms and signs However abdominal pain and hemoperitonium predominated.

\begin{tabular}{ccc}
\hline Clinical presentation & Number of cases & percentage \\
\hline Pain abdomen. & 210 & 42 \\
Hemoperitonium. & 207 & 41.4 \\
Bleeding from wound. & 60 & 12 \\
Shock. & 10 & 2 \\
Brought dead. & 10 & 2 \\
Evisceration. & 3 & 0.6 \\
Total & 500 & 100 \\
\hline
\end{tabular}




\section{Modalities of treatment of abdominal trauma:}

The operative findings revealed injuries to different organs in the abdomen, Hemoperitonium being the common face of presentation. Interestingly, we found that hollow viscera; small bowel as the predominant organ involved $44.76 \%$ (94), Splenic injury was next in the list and a mixed presentation was seen in $2.38 \%$ as depicted in Figure 8.

\section{Organ distribution:}

The above pictures show the different presentations of abdominal trauma (Pictures 1-4).

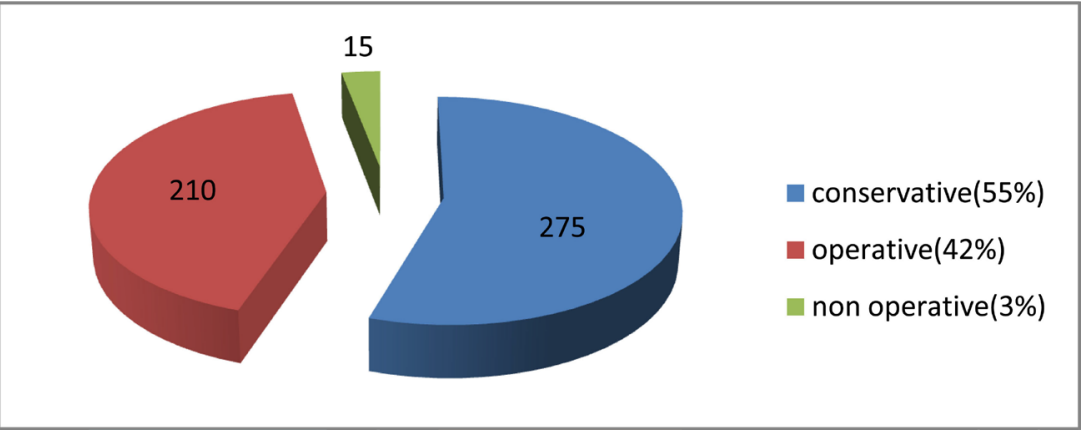

Figure 7. Majority of patients were conservatively managed (55\%).

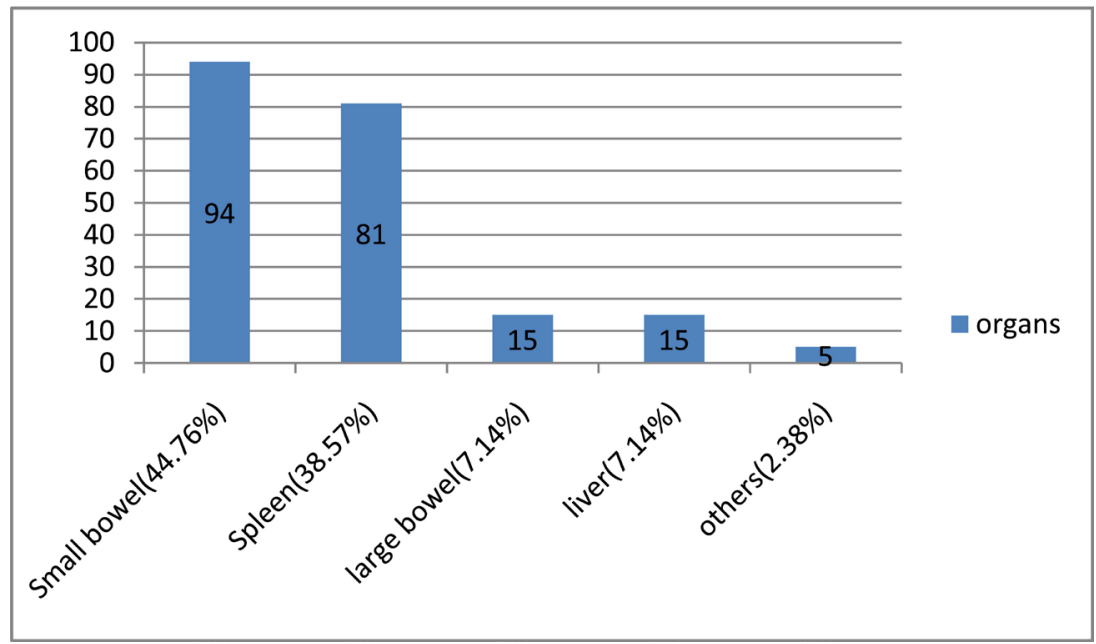

Figure 8. The commonest organ involved in abdominal trauma was small bowel (44.76\%).

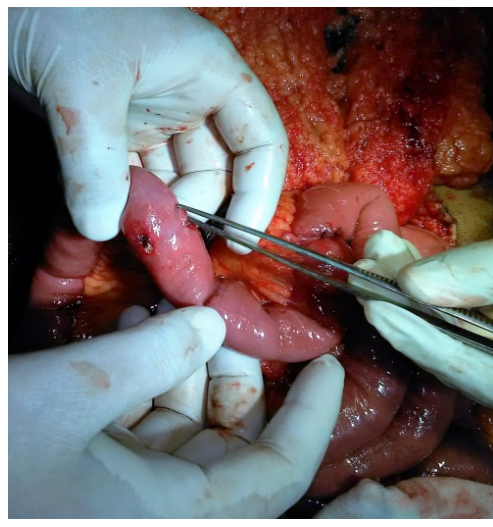

Picture 1. Showing small bowel pellet injury. 


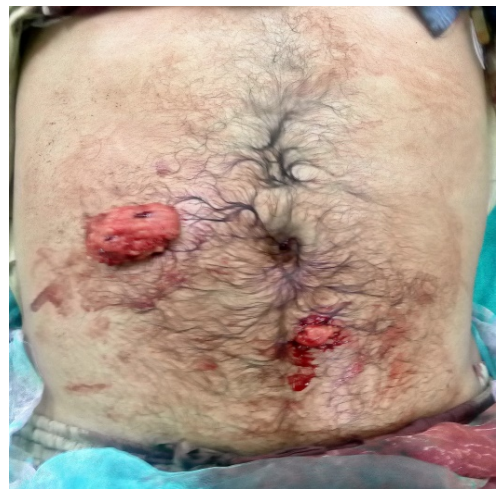

Picture 2. Showing evisceration of omentum.

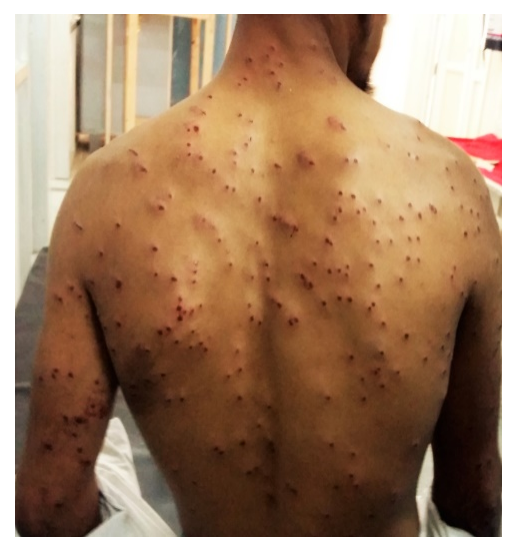

Picture 3. Showing collage of pellets.

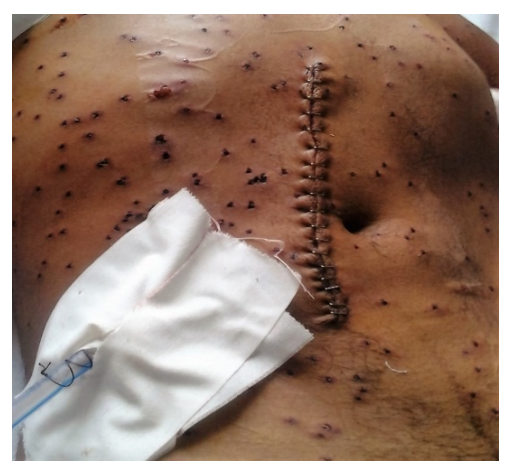

Picture 4. Showing exploratory laparotomy.

\section{Discussion}

The world is on a melting point as newer and newer tragedies strike the mankind. The Disorders and diseases are part of our day to day living. While as medical science has conquered the dreadful diseases to a large extent, yet a newer horizon of man killer diseases are getting explored. It is beyond doubt that natural catastrophes engulf mankind in bulk. The second major killer under the heading of trauma, emerging out as the predominant killer of mankind, is man to man conflict. In view of this, blunt abdominal trauma is on a decline and penetrating abdominal trauma is on surge. While evaluating and analysing the literature available for abdominal trauma: the penetrating abdominal injuries appear to be on the increase due to increase in the inter personal vio- 
lence throughout the world. Penetrating abdominal trauma now accounts for $60 \%$ of the abdominal trauma due to a decline in the blunt abdominal trauma [6].

In another report from southwest Nigeria Ayode et al reported blunt abdominal trauma to the tune of $79.2 \%$ and Penetrating abdominal trauma $20.8 \%$ [7]. In another study from Nigeria; in kanu, a populated urban area in northern Nigeria Edino S.T reported penetrating abdominal trauma 53.7\% and blunt abdominal trauma $46.3 \%$ [8]. In our study, the analysis is almost concordant with the studies published from Nigeria exhibiting the penetrating abdominal trauma to the tune of $60.4 \%$ and blunt abdominal trauma $39.6 \%$. The man to man conflict is the universal disorder and war weaponry modern gadgets are used to surpass each others terrain and domains resulting in massive casualties.

In reference to this it is not out of place to mention that studies are also conducted from Yemen, Syria and Palestine which show the same results as our study. The studies which have already been published from Kashmir valley are also concordant with our study in this regard. The study published from Sheri-Kashmir institute of medical sciences by Ghulam Nabi et al. shows a penetrating injuries of $52.77 \%$ and non penetrating injuries in 47.23\%: However the pattern of injury was gunshot [9]. Males constitiute the great majority of patients across the United States approximately $90 \%$ with penetrating trauma [10].

This compares with our study showing a figure of $95.2 \%$ as males and $4.8 \%$ as females. Males are more resilient and constitute an active aggressive segment of population. In our study the peculiarity about the male involvement observed was little different. The young age segment of our population, who have grown in the conflict zone showed a maximum involvement in this turmoil about $80 \%(15-30)$ years of age. Osime and Oludiran showed that 21 to 30 year age group was the most vulnerable (41.2\%). Navsaria et al. study showed a mean age of 29.5 years [11].

Our study showed a little different face of males being involved in the turmoil. The majority of the victims were in the young age group which was rather disturbing as this is the career making age and constitutes the productive segment of the society. Penetrating abdominal trauma may result from firearm, knives and broken glass pieces. $80 \%$ of penetrating injuries are due to firearm and $20 \%$ due to stab wounds [12]. Our current study of analysis revealed $69.8 \%$ penetrating injuries caused by pellets. We strongly feel that the decline may only be possible if the youths in the society are addressed and their conflicts are listened to their satisfaction.

However, appropriate legislation and enforcement against the use of lethal weapons is strongly recommended. The common organ injury was perforation of small intestine. This is not surprising because the small gut and omentum occupy a large area of the abdominal cavity.

Some studies have advocated adoption of conservative management of penetrating abdominal injury especially when caused by stab wounds. In our study we followed a scientific protocol of management given the gamut of history, clinical presentation and imaging. We devised the treatment protocol as conservative, non operative and operative. The patients who had a fleeting abdominal injury without any clinical evidence of shock, haemoperitoneum, and imaging did not reveal any positive finding of intra-ab- 
dominal viscus injury, were managed conservatively which comprised about $55 \%$ of the total number of patients.

Other group of patients, who were clinically unstable, reported in a shock like picture with clinical presentation of intra-abdominal injuries, were directly sent to the theatre and an attempt of FAST performed reported hemoperitoneum; were explored through a proper laparotomy. This comprised around $42 \%$ of patients. We did have patients in whom the clinical presentation was unstable at the time of reporting; with resuscitation and ward management, daily observations with vital charts and monitoring responded to a so called non-operative management of treatment. It is imperative to mention here that ideally these were the patients who could have been sent for laparotomy; the idea to manage them non-operatively was to avoid an otherwise laparotomy. This was done with a thin margin of safety but with a thick margin of day to day rigorous monitoring of these patients through vital charts and serial imagings.

It comprised a small segment of trauma victims to the tune of $3 \%$. Bowel injuries are a leading cause of morbidity and mortality following trauma. We recorded a mortality of $2 \%$ [10]. The mortality recorded was due to the fact that most of these severely injured patients had developed an exsanguinating shock prior to hospitalization as there is no pre-hospital care in the form of on spot resuscitation and brisk transportation.

However the ones, who died in the hospital, were due to refractory haemorrhage; and few died of the post operative sepsis and multi organ failure. The average mortality rate for all patients with penetrating abdominal trauma is approximately $5 \%$ in most level 1 trauma centres. Van Brussel and Van Hee reported 8.8\% mortality [13]. Shock was responsible for the death in all these patients with fatal outcome.

In summary, our study reflected an otherwise different scenario of abdominal trauma victims. This was a short analysis due to time and again uprisings in Kashmir valley with a new face of penetrating abdominal trauma. The analysis of 500 trauma victims showed an unusual age group of teenage victims and males being predominantly involved. Pellet injury was the commonest mode of injury and penetrating trauma was on upsurge. Majority of our patients were handled with conservative and operative line of treatment.

\section{Conclusion}

Kashmir valley is a conflict zone and time and again uprisings are order of the day. We at Government Medical College Srinagar, at a tertiary care hospital and the only trauma centre available, are used to handle the trauma victims over last 3 decades. We have shown encouraging results amidst of paucity of well designated trauma and triage centres and skilled personnel. The current turmoil was third time seen in the consequent running decade. An inference from this short study of analysis of 500 victims has explored newer problems of the on going conflict and taught us to handle them with otherwise meagre infrastructure available. The limitation of the study was that we had a short time for the upheaval and the follow-up of the patients couldn't be undertaken. It is imperative to convey from this study that a well structured trauma centre is the need of the hour and personnel skilled in handling trauma victims are required in larger numbers; as otherwise the newer turmoil may go beyond control. Pre-hospital on spot 
resuscitation, brisk transportation, well equipped ICU mobile ambulances can go a long way in declining the mortality of these trauma victims.

\section{References}

[1] Fitzgerald, J.E.F. and Larvin, M. (2009) Chapter 15: Management of Abdominal Trauma. In: Baker, Q. and Aldoori, M., Eds., Clinical Surgery: A Practical Guide, CRC Press, 192204.

[2] Jansen, J.O., Yule, S.R. and Loudon, M.A. (2008) Investigation of Blunt Abdominal Trauma. BMJ, 336, 938-942. https://doi.org/10.1136/bmj.39534.686192.80

[3] Wyatt, J., Illingworth, R.N., Graham, C.A., Clancy, M.J. and Robertson, C.E. (2006) Oxford Handbook of Emergency Medicine. Oxford University Press, 346. https://doi.org/10.1093/med/9780199206070.001.0001

[4] Yeo, A. (2004) Abdominal Trauma. In: Chih, H.N. and Ooi, L.L., Eds., Acute Surgical Management, World Scientific Publishing Company, 327-333. https://doi.org/10.1142/9789812563033_0020

[5] Hemmila, M.R. and Wahl, W.L. (2005) Management of the Injured Patient. In: Doherty, G.M., Ed., Current Surgical Diagnosis and Treatment, McGraw-Hill Medical, 227-228.

[6] Osime, C.O. and Oludiran, O.O. (2004) Penetrating Abdominal Injury Cases Admitted in University of Benin Teaching Hospital. Ann Biomed Sci, 3, 39-44.

[7] Ayoade, B.A., Salami, B.A., Tade, A.O., Musa, A.A. and Olawoye, O.A. (2006) Abdominal Injuries in Olabisi Onabanjo University Teaching Hospital, Sagamu, Nigeria. Nigerian Journal of Orthopaedics and Trauma, 5, 45-49.

[8] Edino, S.T. (2003) Pattern of Abdominal Injuries in Aminu Kano Teaching Hospital, Kano. Nigerian Postgraduate Medical Journal, 10, 56-59.

[9] Lone, G.N. and Peer, G.Q. (2001) An Experience with Abdominal Trauma in Adults in Kashmir. 8.

[10] Offner, P., Geibel, J., Stanton-Maxe, K.J., Bjerke, H.S., et al. (2012) Penetrating Abdominal Trauma. http://emedicine.medscape.com/article/2036859

[11] Navsaria, P.H., Berli, J.U., Edu, S. and Nicol, A.J. (2007) Non-Operative Management of Abdominal Stab Wounds: An Analysis of 186 Patients. South African Journal of Surgery, 45, 128-130.

[12] Hoyt, D.B. and Mossa, A.R. (1995) Abdominl Injuries. In: Cuschieri, A., Giles, G.R. and Mossa, A.R., Eds., Essential Surgical Practice, Vol. 3, Butter Worth Heinemann, Boston, 531-544.

[13] Van Brussel, M. and Van Hee, R. (2001) Abdominal Stab Wounds: A Five Year Patient Review. European Journal of Emergency Medicine, 8, 83-88. https://doi.org/10.1097/00063110-200106000-00002 
Submit or recommend next manuscript to SCIRP and we will provide best service for you:

Accepting pre-submission inquiries through Email, Facebook, LinkedIn, Twitter, etc. A wide selection of journals (inclusive of 9 subjects, more than 200 journals) Providing 24-hour high-quality service

User-friendly online submission system

Fair and swift peer-review system

Efficient typesetting and proofreading procedure

Display of the result of downloads and visits, as well as the number of cited articles Maximum dissemination of your research work

Submit your manuscript at: http://papersubmission.scirp.org/

Orcontact ss@scirp.org 